\title{
Biochemical Markers Associated with COVID-19 Disease Severity in a Tertiary Care Teaching Hospital
}

\author{
Minal M Pore ${ }^{1}$, Meghana K Padwal², Annapurna V Raichurkar ${ }^{3}$
}

\begin{abstract}
Aims and objectives: The coronavirus disease-2019 (COVID-19) pandemic has led to an urgent need for reliable biomarkers to identify disease severity. Infection with COVID-19 is rapidly spreading posing a serious threat to community health. This study aims to identify the most effective biomarker among C-reactive protein, procalcitonin, lactate dehydrogenase, and ferritin to predict disease severity. The routine biochemical markers (LFT, RFT, electrolytes, CKNAC, CKMB, blood glucose level) were also evaluated for correlation with disease severity.

Materials and methods: The present study is retrospective type. The study protocol was approved by IEC. The levels of biochemical markers of admitted COVID-19 positive patients were analyzed after determining the normal distribution and their significance was determined by calculating the $p$ value. The accuracy of the biomarkers [C-reactive protein (CRP), PCT, lactate dehydrogenase (LDH), and ferritin] was checked using ROC analysis.

Results: Five hundred and ninety-one COVID-19 positive patients admitted to the hospital (from May 2020 to December 2020) were considered for the study. Out of these 231 (39.1\%) were admitted to the intensive care unit (ICU) and $360(61 \%)$ were in-ward patients. The mean age of the study population was $50.39 \pm 16.7$, with ICU patients significantly older than non-ICU patients $(p<0.001)$ and $50-75$ years being the most common age group. There was a statistically significant difference in the values of CRP, LDH, PCT, ferritin, AST, albumin, urea, CKNAC, sodium, potassium, and blood glucose levels ( $p$ value $<0.05$ )

Conclusion: The severity of COVID-19 disease can be identified at an early stage by following the different routine biochemical marker levels and subsequently improve prognosis. Inflammatory markers (CRP, PCT, LDH, and ferritin) serve as useful guidance for determining disease severity in COVID-19 patients.
\end{abstract}

Keywords: Biomarkers, Coronavirus disease-2019, C-reactive protein, Ferritin, Lactate dehydrogenase, Procalcitonin.

Indian Journal of Medical Biochemistry (2021): 10.5005/jp-journals-10054-0183

\section{INTRODUCTION}

Coronavirus disease-2019 (COVID-19) is a form of zoonosis caused by the novel coronavirus which has caused a global pandemic emergency. The fatality rate due to COVID-19 is lower than the previous two coronavirus diseases [i.e., severe acute respiratory syndrome (SARS) and the Middle East respiratory syndrome (MERS)] but the long incubation period and non-availability of effective antiviral therapy has led to many casualties creating havoc all over the world. Although the clinical characteristics of COVID-19 have been defined, ${ }^{2}$ research on laboratory abnormalities found in patients with COVID-19 is still less known.

Symptoms of the disease in most of the patients are usually seen within a week and consist of fever (body temperature $37-38^{\circ} \mathrm{C}$ ), dry cough, and malaise. About $17 \%$ of cases may progress to severe pneumonia complicated with acute respiratory distress syndrome (ARDS), multi-organ failure, and septic shock. ${ }^{1,3,4}$ Many recently published articles have reported the epidemiological and clinical features of patients with COVID-19 disease, but data regarding the laboratory characteristics of infected individuals are limited. ${ }^{5-7}$ Biochemical parameters between mild and severe cases of COVID19 show significant differences in tests of liver function such as bilirubin (Total and direct), aspartate transaminase (AST), alanine transaminase (ALT), total protein, albumin; glomerular function, i.e., urea, creatinine, and cardiac function such as troponin I and creatine kinase (CKMB and CKNAC). It is also seen that a very high level of procalcitonin, ferritin, lactate dehydrogenase (LDH), and C-reactive protein (CRP) is associated with an increased rate of

\footnotetext{
${ }^{1-3}$ Department of Biochemistry, Bharati Vidyapeeth (Deemed to be University) Medical College and Research Centre, Pune, Maharashtra, India

Corresponding Author: Minal M Pore, Department of Biochemistry, Bharati Vidyapeeth (Deemed to be University) Medical College and Research Centre, Pune, Maharashtra, India, Phone: +91 9730540558, e-mail: minalpore33@gmail.com

How to cite this article: Pore MM, Padwal MK, Raichurkar AV. Biochemical Markers Associated with COVID-19 Disease Severity in a Tertiary Care Teaching Hospital. Indian J Med Biochem 2021;25(2): 83-87.

Source of support: Nil

Conflict of interest: None
}

intensive care unit (ICU) admissions as compared with those of non-ICU dependent patients. ${ }^{8-10}$

Specific biochemical parameters like ferritin, CRP, LDH, and procalcitonin can be used for assessing disease severity in such patients. ${ }^{11}$ Thus, this study aims to provide an insight into the biochemical abnormalities seen in patients with COVID-19.

\section{Materials and Methods}

This study is retrospective type. The COVID positive patients' data were stratified into two groups depending on their severity. ${ }^{12}$ Mild and moderate patients' data who required in-ward hospitalization

(อ) The Author(s). 2021 Open Access This article is distributed under the terms of the Creative Commons Attribution 4.0 International License (https://creativecommons. org/licenses/by-nc/4.0/), which permits unrestricted use, distribution, and non-commercial reproduction in any medium, provided you give appropriate credit to the original author(s) and the source, provide a link to the Creative Commons license, and indicate if changes were made. The Creative Commons Public Domain Dedication waiver (http://creativecommons.org/publicdomain/zero/1.0/) applies to the data made available in this article, unless otherwise stated. 
were put in one group and those having severe disease requiring ICU care were put in the other group. The investigation results data of patients from May 2020 to December 2020 was collected from Laboratory Information System (LIS) and analyzed statistically with appropriate tests, by using Prism (Graph pad Software, San Diego, CA, USA) software package.

\section{Inclusion Criteria}

All patients $\geq 18$ years of age positive for COVID-19 disease by RT-PCR. ${ }^{13}$

\section{Exclusion Criteria}

COVID-19 positive patients not requiring hospital admission/OPD patients.

The biochemical markers were analyzed after determining the normal distribution and their significance was determined by calculating the $p$ value by unpaired $t$-test for normally distributed data and by Mann-Whitney $U$ test for the rest. The accuracy of the biomarkers (CRP, PCT, LDH, and ferritin) was checked using $\mathrm{ROC}$ analysis. The biochemical parameters were estimated by commercially available standard kits with internationally accepted methods on fully automated analyzers - IMOLA by Randox and iArchitect by Abbott diagnostics. The research protocol was approved by the Institutional Ethics Committee (certificate no. BVDUMC/IEC/19).

\section{Results}

Five hundred and ninety-one COVID-19 positive patients admitted to the hospital (from May 2020 to December 2020) were considered for the study. Out of these majority of patients (61\%) who had mild to moderate symptoms were admitted in wards, and those having severe disease (39.1\%) were admitted to the ICU. The mean age of the study population was $50.39 \pm 16.7$. The most common age group was between 50 years and 75 years, with ICU patients significantly older than non-ICU patients $(p<0.001)$. There was no significant difference in the distribution of patients based on gender (Table 1).

The laboratory investigation showed the ICU patients to be having significantly higher values of inflammatory markers CRP, ferritin, $\mathrm{LDH}$, and procalcitonin than the non-ICU patients. The routine biochemical parameters thereof, total bilirubin, direct bilirubin, total protein, albumin, AST, urea, creatinine, sodium, and potassium were also seen to be significantly deranged in the patients admitted in ICU suggesting profound liver and renal damage in these patients (Table 2).

Receiver operator characteristics were performed and area under the curve (AUC) values were determined. Area under the curve for significant parameters is shown in Table 3 and Figure 1, $\mathrm{LDH}$ showing the maximum area under the curve suggesting to be the one of the best marker for predicting disease severity in COVID-19 patients. The AUC suggests that the probability of the particular biomarker is higher for the severe patients (ICU group) than that for the non-severe patients (non ICU group).

\section{Discussion}

The ongoing COVID-19 pandemic has propelled an urgent need to explore effective disease severity predictors. The present study establishes biomarkers that can accurately predict the severity of COVID-19 patients. Our study showed that LDH is significantly increased in patients experiencing a severe course of the disease compared with those with mild disease. The AUC was highest for LDH in our study thereby demonstrating its role as the most potential biomarker in predicting COVID-19 severity. A study conducted in Changsha by Zheng et al. also observed LDH as an important biomarker for disease severity. ${ }^{17}$ In their study, LDH levels were significantly elevated in patients with severe COVID-19. Chen et al. also documented an association of elevated levels of LDH in patients with disease severity. ${ }^{18}$ Their research, as well as ours, concluded a substantial association between LDH levels and disease severity. Lactate dehydrogenase levels are predicted to be high in these patients due to increased vascular permeability in immunemediated lung injury and hemolysis. ${ }^{19,20}$

Our analysis showed that CRP is significantly elevated in severe cases when compared with mild ones $(p<0.001)$ which was in concordance with a study conducted by Qin et al. who in their research has stressed the use of CRP to predict disease prognosis ( $p$ value $<0.001$ ). ${ }^{21}$ Gao et al. have reached the same conclusion but in our study, the AUC of CRP was 0.600 which was much higher than their study. ${ }^{8}$ The conclusion reached by Zheng et al. in identifying CRP as a significant marker for predicting the severe manifestation of COVID-19 is similar to ours. ${ }^{22}$ Their values of milder disease, along with another study, were similar to our findings. ${ }^{17,22} \mathrm{C}$-reactive protein levels are considered to be elevated in COVID-19 disease as CRP activates the complement

Table 1: Demographic distribution of patient data

\begin{tabular}{|c|c|c|c|c|c|}
\hline S. no. & Characteristics & Total $(n=591)$ & $\operatorname{ICU}(n=231)$ & Non-ICU $(n=360)$ & pvalue \\
\hline \multirow[t]{3}{*}{1} & Age & $50.39 \pm 16.7$ & $56.8 \pm 13.8$ & $46.2 \pm 17$ & $<0.001$ \\
\hline & Age (males) & $51.8 \pm 16.6$ & $58.02 \pm 13.8$ & $47.5 \pm 17.17$ & $<0.001$ \\
\hline & Age (females) & $56.8 \pm 13.9$ & $54.15 \pm 13.81$ & $43.97 \pm 16.86$ & $<0.001$ \\
\hline \multirow[t]{5}{*}{2} & Age groups & $n(\%)$ & $n(\%)$ & $n(\%)$ & \\
\hline & $15-25$ & $38(6.4)$ & $2(5.1)$ & $37(94)$ & $<0.001^{*}$ \\
\hline & $26-50$ & $246(41.6)$ & 76 (30.9) & $173(70.3)$ & \\
\hline & $51-75$ & $275(46.5)$ & $140(50.9)$ & $135(49.1)$ & \\
\hline & $>75$ & $31(5.2)$ & $16(51.6)$ & $15(48.4)$ & \\
\hline \multirow[t]{3}{*}{3} & Hospital admission & $n(\%)$ & $n(\%)$ & $n(\%)$ & \\
\hline & Males & $387(65.4)$ & $159(41)$ & $228(58.9)$ & $0.17^{*}$ \\
\hline & Females & $204(34.5)$ & $72(35.2)$ & $132(64.7)$ & \\
\hline
\end{tabular}

${ }^{*} p$ value by Chi-square test 
Table 2: Comparison of laboratory investigations among patients of COVID-19

\begin{tabular}{|c|c|c|c|c|c|}
\hline S. no. & Parameter & Reference range $e^{14-16}$ & $I C U$ & Non-ICU & $p$ value \\
\hline 1 & C-reactive protein & $0-5 \mathrm{mg} / \mathrm{L}$ & $124(65-198)$ & $40(14-100)$ & $<0.001$ \\
\hline 2 & Procalcitonin & $<0.05 \mathrm{ng} / \mathrm{mL}$ & $0.25(0.09-1.2)$ & $0.06(0.03-0.19)$ & $<0.001$ \\
\hline 3 & Ferritin & $\begin{array}{l}\text { Males: } 21.8-274.6 \mathrm{ng} / \mathrm{mL} \text {, Females: } \\
4.63-204 \mathrm{ng} / \mathrm{mL}\end{array}$ & 467 (246-969) & $271(124-558)$ & $<0.001$ \\
\hline 4 & $\mathrm{LDH}$ & $230-460 \mathrm{IU} / \mathrm{L}$ & $1,001(789-1,222)$ & $614(441-850)$ & $<0.001$ \\
\hline 5 & T. bilirubin & $0.2-1 \mathrm{mg} / \mathrm{dL}$ & $0.69(0.48-0.99)$ & $0.57(0.4-0.86)$ & $<0.001$ \\
\hline 6 & D. bilirubin & $0.1-0.3 \mathrm{mg} / \mathrm{dL}$ & $0.22(0.13-0.37)$ & $0.17(0.11-0.28)$ & $<0.001$ \\
\hline 7 & AST & $5-35 \mathrm{IU} / \mathrm{L}$ & $47.5(31-76)$ & $35(20-60)$ & $<0.001$ \\
\hline 8 & ALT & $5-40 \mathrm{IU} / \mathrm{L}$ & $33(22-58)$ & $32(18-52)$ & 0.179 \\
\hline 9 & ALP & 98-279 IU/L & $233(182-323)$ & $229.5(171-283)$ & 0.196 \\
\hline 10 & Total protein & $6-8 \mathrm{~g} / \mathrm{dL}$ & $6.3(5.8-6.8)$ & $6.6(6.1-6.9)$ & 0.0002 \\
\hline 11 & Albumin & $3.5-5.2 \mathrm{~g} / \mathrm{dL}$ & $3.7(3.5-4.4)$ & $4.1(3.7-4.3)$ & $<0.001$ \\
\hline 12 & Urea & $10-45 \mathrm{mg} / \mathrm{dL}$ & $42.5(27-59)$ & $21.5(14.2-31)$ & $<0.001$ \\
\hline 13 & Creatinine & $\begin{array}{l}\text { Males: } 0.9-1.3 \mathrm{mg} / \mathrm{dL} \text {, Females: } \\
0.6-1.1 \mathrm{mg} / \mathrm{dL}\end{array}$ & $1(0.8-1.3)$ & $0.9(0.8-1.1)$ & 0.04 \\
\hline 14 & Sodium & $136-145 \mathrm{mEq} / \mathrm{L}$ & $135 \pm 5.1$ & $134 \pm 4.9$ & 0.01 \\
\hline 15 & Potassium & $3.5-5.1 \mathrm{mEq} / \mathrm{L}$ & $4.4 \pm 0.9$ & $4.1 \pm 0.7$ & $<0.001$ \\
\hline 16 & Troponin I & $0-0.04 \mathrm{ng} / \mathrm{mL}$ & $0.01(0.01-0.06)$ & $0.01(0.01-0.012)$ & 0.184 \\
\hline 17 & CKNAC & 25-200 IU/L & $95(60-479)$ & $58(43.7-196.8)$ & 0.029 \\
\hline 18 & CKMB & $0-24$ IU/L & $41(25-64)$ & $32(19-53)$ & 0.06 \\
\hline 19 & Random glucose & $70-140 \mathrm{mg} / \mathrm{dL}$ & $160(127-235)$ & 125 (103-207) & 0.003 \\
\hline
\end{tabular}

Table 3: Area under the curve values for significant parameters

\begin{tabular}{llllc}
\hline S.no. & Variable & AUC & $95 \% \mathrm{Cl}$ & p value \\
\hline 1 & CRP & 0.754 & $0.7089-0.7993$ & $<0.001$ \\
2 & LDH & 0.771 & $0.729-0.814$ & $<0.001$ \\
3 & PCT & 0.736 & $0.688-0.783$ & $<0.001$ \\
4 & Ferritin & 0.647 & $0.596-0.698$ & $<0.001$ \\
5 & AST & 0.613 & $0.559-0.667$ & $<0.001$ \\
6 & Albumin & 0.668 & $0.616-0.720$ & $<0.001$ \\
7 & Urea & 0.681 & $0.630-0.732$ & $<0.001$ \\
8 & CKNAC & 0.629 & $0.518-0.739$ & 0.02 \\
9 & BGL & 0.612 & $0.538-0.686$ & 0.003 \\
\hline
\end{tabular}

system and enhances phagocytosis for enhancing the clearance of virus from the body.

The significance of ferritin as a biomarker to monitor and predict disease severity as compared to CRP and LDH was much lower in our study. This conclusion differs from what is reported by many other studies, most of them identifying serum ferritin to be a significant marker for the prediction of disease severity. ${ }^{18,23}$ A study in Wuhan, China, found a strong association of serum ferritin as a marker for severe disease. ${ }^{21}$ The association between the levels of ferritin and disease severity was closer to our study in terms of statistics, with our study reporting a $p$ value of $<0.001$ at admission compared with their $p$ value of $0.049 .{ }^{18}$ Increased serum ferritin concentration is due to the production of cytokines by macrophages and as macrophages account for the majority of the immune cells in the lung parenchyma, they are responsible for the secretion of serum ferritin. Additionally, ferritin synthesis can be induced by several inflammatory stimuli like IL- 6 which are known to be elevated in COVID-19 disease. ${ }^{24}$

Our results also demonstrated the use of $\mathrm{PCT}$ to be a significant biomarker of the disease, which is dissimilar to the conclusions reached by Gao et al., where the authors did not find a significant association between PCT and disease severity. ${ }^{8}$ On the contrary, several studies have reported a significant association between the elevated levels of PCT and disease severity. ${ }^{17,25}$ This association seen in our study between PCT and its predictability of disease severity may be due to the higher rates of bacterial co-infection and ventilator-associated pneumonia.

Cardiac markers (troponin I and CKMB) were not effective in predicting the severity in our study which was dissimilar to the findings by Tersalvi et al. ${ }^{26}$ Regarding the laboratory investigations total and direct bilirubin, total protein, albumin, AST, urea, creatinine, sodium, potassium, and glucose were all associated with disease severity in our study, a finding similar to many previously conducted research studies. ${ }^{22,27}$

However, there were few limitations in our study, the major one being the confounding factors of various comorbidities that may be the cause of severe immune dysregulation in certain patients. Also, secondary bacterial infections and multi-organ failure can also aggravate the immune dysfunction, which cannot be solely attributed to the viral agent being studied.

\section{Conclusion}

We studied the effect of various biochemical markers in the severity of COVID-19 and the order of effectiveness among the markers. Our findings concluded that LDH and CRP were superior to serum ferritin and PCT as an effective biomarker in predicting 

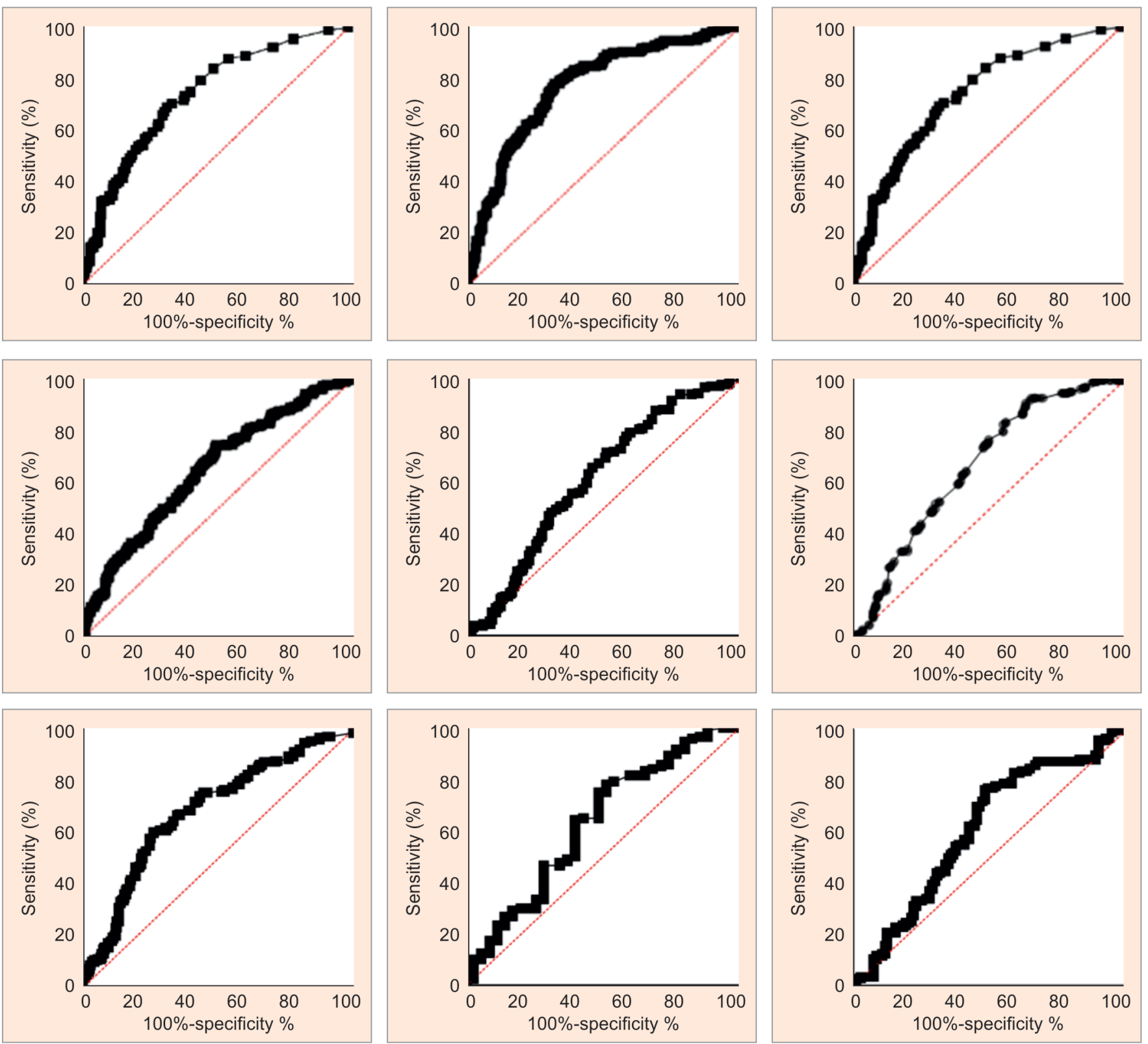

Figs $1 \mathrm{~A}$ to I: ROC curves of significant parameters

the severity of COVID-19. The severity of COVID-19 can be identified at an early stage by following the different routine biochemical marker levels and subsequently improve prognosis. Inflammatory markers ( $\mathrm{LDH}, \mathrm{CRP}, \mathrm{PCT}$, and ferritin) serve as useful guidance for determining disease severity in COVID-19 patients in this region with COVID-19.

\section{References}

1. Organization $\mathrm{WH}$, Clinical management of severe acute respiratory infection (SARI) when COVID-19 disease is suspected: interim guidance, 13 March 2020. World Health Organization, 2020.

2. Mattiuzzi C, Lippi G. Which lessons shall we learn from the 2019 novel coronavirus outbreak? Ann Transl Med 2020;8(3):48. DOI: 10.21037/ atm.2020.02.06.
3. Guan W, Ni Z, Hu Y, et al. Clinical characteristics of coronavirus disease 2019 in China. N Eng J Med 2020;80(6):656-665. DOI: 10.1056/ NEJMoa2002032.

4. Ai T, Yang Z, Hou H, et al. Correlation of chest CT and RT-PCR testing in coronavirus disease 2019 (COVID-19) in China: a report of 1014 cases. Radiology 2020(2):200642. DOI: 10.1148/radiol. 2020200642

5. Rodriguez-Morales AJ, Cardona-Ospina JA, Villamizar-Pena R, et al. Clinical, laboratory and imaging features of COVID-19: a systematic review and meta-analysis. Travel Med Infect Dis 2020. 101623. DOI: 10.1016/j.tmaid.2020.101623.

6. Yang X, Yu Y, Xu J, et al. Clinical course and outcomes of critically ill patients with SARSCoV-2 pneumonia in Wuhan, China: a singlecentered, retrospective, observational study. Lancet Respirat Med 2020;8(5):P475-P481. DOI: 10.1016/S2213-2600(20)30079-5. 
7. Liu K, Fang Y-Y, Deng $Y$, et al. Clinical characteristics of novel coronavirus cases in tertiary hospitals in Hubei Province. Chin Med J 2020;133(9):1025-1031. DOI: 10.1097/CM9.0000000000000744.

8. Gao Y, Li T, Han M, et al. Diagnostic utility of clinical laboratory data determinations for patients with the severe COVID-19. J Med Virol 2020;92(7):791-796. DOI: 10.1002/jmv.25770.

9. Mardani R, Vasmehjani AA, Zali F, et al. Laboratory parameters in detection of COVID-19 patients with positive RT-PCR; a diagnostic accuracy study. Archi Acade Emerg Med 2020;8(1):e43.

10. Xiang J, Wen J, Yuan X, et al. Potential biochemical markers to identify severe cases among COVID-19 patients. medRxiv 2020. preprint 10.1101/2020.03.19.20034447.

11. Al Ghamdi M, Alghamdi KM, Ghandoora Y, et al. Treatment outcomes for patients with middle Eastern respiratory syndrome coronavirus (MERS CoV) infection at a coronavirus referral center in the Kingdom of Saudi Arabia. BMC Infect Dis 2016;16(1):17. DOI: 10.1186/s12879-0161492-4.

12. https://www.mohfw.gov.in/pdf/ClinicalManagement ProtocolforCOVID19.pdf.

13. Strategy for COVID19 testing in India (Version 5, dated 18/05/2020).

14. Randox Kit Inserts, Abbott kit inserts and Quidel Triage Troponin Panel for considered parameters.

15. Burtis C, Ashwood E, Bruns D. Tietz textbook of clinical chemistry and molecular diagnostics. 5th ed., Ch. 60, Elsevier; 2012. p. 2131.

16. Mcpherson P. Henry's clinical diagnosis and management by laboratory methods. Appendix 5, Table A5-4, 23rd ed., Elsevier; 2007. p. 1555.

17. Zheng F, Tang W, Li H, et al. Clinical characteristics of 161 cases of coronavirus disease 2019 (COVID-19) in Changsha. Eur Rev Med Pharmacol Sci 2020;24(6):3404-3434. DOI: 10. 10.26355/ eurrev_202003_20711.

18. Chen G, Wu D, Guo W, et al. Clinical and immunological features of severe and moderate coronavirus disease 2019. J Clin Invest 2020;130(5):2620-2629. DOI: 10.1172/JCl137244.
19. Szarpak L, Ruetzler K, Safiejko K, et al. Lactate dehydrogenase level as a COVID-19 severity marker. Am J Emerg Med 2021;45:638-639. DOI: 10.1016/j.ajem.2020.11.025.

20. Lopez C, Kim J, Pandey A, et al. Simultaneous onset of COVID-19 and autoimmune haemolytic anaemia. Br J Haematol 2020;190(1):31-32. DOI: $10.1111 /$ bjh.16786.

21. Qin C, Zhou L, Hu Z, et al. Dysregulation of immune response in patients with COVID-19 in Wuhan, China. Clin Infect Dis 2020;71(15):762-768. DOI: 10.1093/cid/ciaa248.

22. Zheng $Y, X u H$, Yang $M$, et al. Epidemiological characteristics and clinical features of 32 critical and 67 noncritical cases of COVID-19 in Chengdu. J Clin Virol 2020;127:104366. DOI: 10.1016/j.jcv.2020. 104366.

23. Carubbi F, Salvati L, Alunno A, et al. Ferritin is associated with the severity of lung involvement but not with worse prognosis in patients with COVID-19: data from two Italian COVID-19 units. Sci Rep 2021;11:4863. DOI: 10.1038/s41598-021-83831-8.

24. Ruscitti P, Berardicurti O, Barile A, et al. Severe COVID-19 and related hyperferritinaemia: more than an innocent bystander? Ann Rheuma Dis 2020;79(11):1515-1516. DOI: 10.1136/annrheumdis-2020217618.

25. Liu F, Li L, Xu M, et al. Prognostic value of interleukin-6, C-reactive protein, and procalcitonin in patients with COVID-19. J Clin Virol 2020;127:104370. DOI: 10.1016/j.jcv.2020.104370.

26. Tersalvi G, Vicenzi M, Calabretta D, et al. Elevated troponin in patients with coronavirus disease 2019: possible mechanisms. J Card Fail 2020;26(6):470-475. DOI: 10.1016/j.cardfail.2020. 04.009.

27. Asghar MS, Haider Kazmi SJ, Ahmed Khan N, et al. Clinical profiles, characteristics, and outcomes of the first 100 admitted COVID-19 patients in Pakistan: a single-center retrospective study in a tertiary care hospital of Karachi. Cureus 2020;12(6):e8712. DOI: 10.7759/ cureus.c34. 